\title{
DETERMINAN PILIHAN KARIR MAHASISWA FAKULTAS KEDOKTERAN SEBAGAI SPESIALIS DI INDONESIA
}

\author{
Rizma Adlia Syakurah*, Dwi Atika Sari**, Dendy Riansyah**, Priska Yolanda** \\ * Departemen IImu Kesehatan Masyarakat, Fakultas Kedokteran, Universitas Sriwijaya \\ ** Program Studi S1 Pendidikan Kedokteran Umum, Fakultas Kedokteran, Universitas Sriwijaya
}

\begin{abstract}
Background: In this "Jaminan Kesehatan Nasional" (JKN) era, career preference among medical students became an important issue to be concerned with, especially regarding career as a specialist physician in order to ensure equal distribution of doctor's quantity and profession variation. Several studies had been conducted abroad with aim to analyse career preference's determinants of medical students, but these kind of studies are rarely found in Indonesia. The objective of this study is to analyse the determinants of career preferences in medical speciality among medical students in Indonesia.

Method: Cross-sectional study with questionnaire. Population of the study were first year students in 13 public universities with " $A$ " accreditation. Samples collected by stratified consecutive sampling method. Chi square was used to evaluate the association between career preferences with socio-demographic and academic factors.

Results: Among 315 samples, 83,8\% students chose medical speciality as their preferred career. Determinants which influence career preferences are having parents that works in medical field $(P=0.036)$, higher parents earning $(P=$ 0.04), and deciding to enrol to medical school since before high school $(P=0.036)$.

Conclusion: Parents social economic state and background, along with personal motivation are some of important determinants to be considered. More studies need to be conducted in this area, especially regarding the underlying behaviour that affect further career preferences. Socialization about the importance and merits of other medical professions needs to be implement to prevent gap in medical profession's distribution later on.
\end{abstract}

KEYWORDS: Career preference, medical speciality, medical profession.

\section{ABSTRAK}

Latar belakang: Di saat pemerintah telah menjalankan Jaminan Kesehatan Nasional (JKN) di Indonesia, pemilihan karir menjadi penting untuk diketahui dan dicermati, terutama terkait pilihan sebagai dokter spesialis, demi menjamin pemerataan jumlah beserta jenis profesi dokter. Berbagai penelitian telah dilakukan di luar negeri untuk mengetahui berbagai determinan penentu pilihan karir mahasiswa kedokteran, akan tetapi penelitian serupa belum banyak dilakukan di Indonesia. Tujuan penelitian ini adalah untuk menganalisis determinan pilihan karir mahasiswa kedokteran sebagai spesialis di Indonesia.

Metode: Studi cross-sectional dengan menggunakan kuesioner. Populasi penelitian adalah mahasiswa tahun pertama di 13 universitas negeri di Indonesia dengan Akreditasi A. Penentuan sampel menggunakan stratified consecutive sampling. Chi square digunakan untuk menguji hubungan antara pilihan karir dengan determinan sosio-demografi dan akademis.

Hasil: Dari 315 sampel didapatkan 83,8\% mahasiswa menjadikan spesialis sebagai pilihan karirnya. Determinan yang berpengaruh adalah orang tua yang bekerja di bidang kesehatan $(\mathrm{P}=0.036)$, pendapatan orang tua lebih besar $(\mathrm{P}=0.04)$, dan keputusan untuk masuk fakultas kedokteran sejak sebelum SMA $(\mathrm{P}=0.036)$.

Kesimpulan: Status sosial-ekonomi dan latar belakang orang tua, ditambah dengan motivasi pribadi sejak dini merupakan determinan yang penting untuk diperhatikan. Perlu dilakukan penelitian lebih lanjut terkait perilaku yang mendasari pilihan karir mahasiswa kedokteran, juga perlu dilakukan sosialisasi tentang betapa penting dan

Korespondensi: rizmaadlia@gmail.com 
menguntungkannya profesi kedokteran lain demi mencegah kesenjangan persebaran profesi kedokteran di masa mendatang.

KATA KUNCI: pilihan karir, spesialis, profesi kedokteran

\section{PENDAHULUAN}

Pilihan karir mahasiswa kedokteran merupakan hal yang sangat penting dan kompleks. Selain faktor minat dan bakat, terdapat banyak faktor lain yang mempengaruhi pemilihan karir, seperti prospek masa depan, gaya hidup, jumlah penghasilan, keseimbangan antara pekerjaan dan kehidupan, kepuasan intelektual, jumlah pasien dan faktor demografis, seperti jenis kelamin, usia, dan tempat tinggal. $^{1-8}$

Pemilihan karir merupakan proses yang terus menerus dan berkelanjutan, dimulai sejak umur sangat dini dan terus berevolusi tanpa henti.

Karir seorang dokter dapat dibedakan menjadi dua, yaitu bidang klinis (dokter layanan primer atau spesialis) dan non klinis (kedokteran dasar, kedokteran komunitas, administrasi kesehatan, penelitian, industri farmasi dan lainnya).9,10 Sebagian kecil dokter menempuh karir di luar bidang kedokteran (non medis), seperti wirausaha, politikus, artis, penulis dan lainnya. ${ }^{11}$

Beberapa studi menunjukkan bahwa kebanyakan mahasiswa lulusan fakultas kedokteran lebih memilih spesialisasi klinis dibandingkan menjadi dokter pelayanan primer, bidang non klinis, ataupun non medis. ${ }^{2}$ Faktor-faktor yang berpengaruh dalam hal tersebut adalah penghasilan, persepsi tentang dokter umum, jenis kelamin, pendidikan orang tua, dan penghasilan orang tua. ${ }^{12-17}$

Ketimpangan kesejahteraan dan prestige antara dokter umum-dokter spesialis menyebabkan bidang spesialis masih menjadi pilihan utama bagi kebanyakan mahasiswa kedokteran di Indonesia. Dengan penerapan JKN, pemerintah harus mempercepat upaya penataan ulang sistem layanan primer-sekunder-tersier dan distribusi dokter di Indonesia, sehingga terjadi pemerataan kualitas pelayanan kesehatan. ${ }^{18}$

Faktor-faktor tersebut di atas sebenarnya dapat dimodifikasi dengan penyusunan kebijakan, sehingga bidang kedokteran non klinis secara profesional dan finansial lebih layak. ${ }^{2}$ Cara lain yang dapat dilakukan adalah dengan menyisipkan kurikulum khusus mengenai pentingnya ilmu kedokteran dasar dalam dalam tatalaksana pasien sehingga diharapkan akan ada lebih banyak dokter baru tertarik untuk memilih bidang nonklinis. ${ }^{3}$

Menilik realitas diatas, pemilihan karir mahasiswa kedokteran di Indonesia perlu dikaji lebih dalam. Tidak untuk mengetahui minat mahasiswa kedokteran, tetapi juga untuk mengetahui faktor apa saja yang mempengaruhi pilihan karir sehingga dapat menjadi sumber informasi yang valid untuk dapat menarik minat mahasiswa kedokteran memilih karir yang lebih bervariasi dalam profesi kedokteran.

\section{METODE}

Penelitian ini merupakan studi observasional dengan rancangan cross-sectional dilakukan pada bulan November 2013 untuk menilai korelasi beberapa variabel dengan pemilihan karir.

Penelitian ini dilaksanakan dengan mengirim kuesioner melalui e-mail ke 13 fakultas kedokteran universitas negeri akreditasi A di seluruh Indonesia untuk seluruh mahasiswa tahun pertama. Cara pengambilan sampel adalah stratified consecutive sampling dengan besar sampel minimal 252 orang. Total jumlah sampel yang diharapkan adalah sebanyak 410 kuesioner terisi. Jumlah sampel di tiap universitas dibagi secara proporsional untuk mendapatkan hasil yang lebih representatif.

Variabel terikat pada penelitian ini adalah pilihan karir, sementara itu variabel bebas adalah faktor yang mempengaruhi pilihan karir, antara lain jenis kelamin, sosial-ekonomi orang tua, ketertarikan pribadi dan adanya pengaruh untuk masuk fakultas kedokteran.

\section{HASIL DAN PEMBAHASAN}

Dari penelitian ini didapatkan 315 siswa dari 10 universitas (tingkat respon 76\%). Tingkat respons rendah disebabkan karena kendala koordinasi ke universitasuniversitas tujuan. 


\section{Frekuensi pilihan karir mahasiswa}

Pilihan karir untuk menjadi spesialis dipilih oleh 264 (83.8\%) mahasiswa (Tabel 1). Hasil penelitian ini sesuai dengan hasil penelitian di berbagai negara tentang pilihan karir mahasiswa kedokteran yang cenderung memilih karir di bidang klinis, terutama spesialis. ${ }^{5,17,19}$

Tabel 1. Frekuensi dan persentase pilihan karir

\section{Pilihan Karir Frekuensi Persentase (\%)}

\begin{tabular}{lcc} 
Spesialis & 264 & 83.8 \\
Non spesialis & 51 & 16.2 \\
Total & 315 & 100.0 \\
\hline
\end{tabular}

\section{Determinan pilihan karir mahasiswa}

Pada analisis determinan pilihan karir mahasiswa, ternyata pekerjaan, pendapatan orangtua, dan periode mulai tertarik untuk masuk fakultas kedokteran terbukti secara bermakna mempengaruhi pilihan karir mahasiswa kedokteran. (Tabel 2)

Pengaruh sosial ekonomi orang tua dalam pilihan karir spesialisasi dapat disebabkan karena faktor biaya dan lama pendidikan untuk menjadi dokter spesialis. Jenis pekerjaan orang tua telah terbukti dapat mempengaruhi minat dan bakat anaknya. ${ }^{20}$

Periode ketertarikan masuk FK yang lebih awal adalah sesuai dengan teori Ginzberg yang menyatakan bahwa penentuan karir merupakan suatu proses perkembangan yang terus-menerus, dimulai pada usia dini dan terus berkembang menjadi pilihan karir pada saat dewasa. ${ }^{21}$

Sebaliknya mata pelajaran favorit selama SMA, tidak ada hubungan dengan pilihan karir. Kemungkinan disebabkan oleh pertanyaan yang diajukan pada kuesioner tidak spesifik. Pertanyaan pada kuesioner hanya menyebutkan Ilmu Pengetahuan Alam (IPA). Pernyataan IPA tidak spesifik karena IPA terdiri dari fisika, biologi dan kimia, sehingga menyebabkan pilihan jawaban kuesioner kurang tajam. Akan tetapi, mahasiswa yang pada saat SMA menyukai mata pelajaran IPA akan lebih mungkin memilih karir di bidang spesialisasi klinis dibandingkan dengan mahasiswa yang menyukai mata pelajaran lain di SMA (OR 1,1 CI:0,6-2,1).

Gender tidak berhubungan secara bermakna dengan pilihan karir sebagai spesialis, meskipun demikian ternyata pria $60 \%$ lebih banyak memilih karir sebagai spesialis dibandingkan dengan wanita. Hasil tersebut tidak sesuai dengan penelitian yang menyatakan bahwa terdapat perbedaan terkait gender pada pilihan karir.

Tabel 2. Variabel determinan pilihan karir

\begin{tabular}{llll}
\multicolumn{1}{c}{ Variabel } & OR $(95 \%$ CI $)$ & p \\
$\begin{array}{l}\text { Jenis Kelamin } \\
\text { Pria } \\
\text { Wanita }\end{array}$ & $1,627(0,775$ & $-3,414)$ & 0,198 \\
\hline $\begin{array}{l}\text { Pekerjaan Orang Tua } \\
\text { Keduanya Medis } \\
\text { Salah Satu Medis } \\
\text { Keduanya Non-Medis }\end{array}$ & $2,293(1,057$ & $-4,975)$ & 0,036 \\
\hline $\begin{array}{l}\text { Pendapatan Orang Tiı } \\
>5 \text { juta } \\
<5 \text { juta }\end{array}$ & $2,464(1,328$ & $-4,571)$ & 0,04 \\
\hline $\begin{array}{l}\text { Mata Pelajaran Favorit di SMA } \\
\text { IPA } \\
\text { Lainnya }\end{array}$ & $1,129(0,610$ & $-2,089)$ & 0,699 \\
\hline $\begin{array}{l}\text { Periode Tertarik Masuk FK } \\
\text { Sebelum Masuk SMA } \\
\text { Setelah Masuk SMA }\end{array}$ & $2,147(1,053$ & $-4,377)$ & 0,036 \\
\hline $\begin{array}{l}\text { Pengaruh Masuk FK } \\
\text { Tidak Ada } \\
\text { Ada }\end{array}$ & $1,754(0,891$ & $-3,452)$ & 0,104 \\
\hline
\end{tabular}


Waktu untuk keluarga dan jam kerja yang lebih fleksibel merupakan pertimbangan yang dianggap lebih penting bagi wanita. ${ }^{22}$ Dalam penelitian ini, dimana populasi yang diteliti adalah mahasiswa tahun pertama, maka kemungkinan ada perbedaan persepsi karena usia responden masih muda.

Pada analisis regresi logistik didapatkan bahwa variabel Pendapatan Orang Tua merupakan variabel yang berpengaruh paling tinggi pada penentuan pilihan karir mahasiswa.

Mahasiswa pria, dengan salah satu orang tuanya bekerja dibidang medis, berpendapatan kurang dari 5 juta rupiah, memilih IPA sebagai pelajaran favorit di SMA, tertarik masuk FK sebelum masuk SMA dan tidak dipengaruhi untuk masuk FK berpeluang 97.13\% untuk memilih menjadi spesialis sebagai pilihan karirnya.

Akan tetapi nilai Psudo $\mathrm{R}^{2}$ menyatakan bahwa variabel yang diteliti tersebut hanya menyumbang kurang dari $10 \%$ dari determinan pilihan karir mahasiswa kedokteran

Tabel 3. Nilai R-square pada regresi logistik

\begin{tabular}{ccc}
$\begin{array}{c}\text { McFadden } \\
\text { R - square }\end{array}$ & $\begin{array}{c}\text { Cox \& Snell } \\
\text { R - square }\end{array}$ & $\begin{array}{c}\text { Nagelkerke } \\
\text { R -square }\end{array}$ \\
\hline 0.06 & 0.05 & 0.09 \\
\hline
\end{tabular}

\section{KESIMPULAN}

Dari penelitian ini didapatkan bahwa mahasiswa memiliki ketertarikan yang lebih untuk berkarir di bidang klinis/spesialisasi medis dibandingkan dengan profesi kedokteran lain. Determinan pilihan karir mahasiswa yang terbukti secara bermakna adalah pekerjaan orang tua, pendapatan orang tua, dan periode tertarik masuk FK. Pendapatan orang tua merupakan determinan yang paling bermakna diantara faktor yang diteliti.

\section{SARAN}

Penelitian ini masih memiliki banyak kekurangan, salah satunya adalah kurang luasnya variabel yang diteliti, sehingga disarankan pada penelitian berikutnya dapat menambahkan variabel yang lebih luas lagi, sehingga bisa didapatkan hasil yang lebih kuat terkait alasan pemilihan karir.
Selain itu, karena penelitian ini hanya terbatas pada mahasiswa di tahun pertama, untuk selanjutnya bisa diperluas pada semua tahapan pendidikan mahasiswa kedokteran. Penelitian lebih lanjut diharapkan dapat melengkapi kekurangan tersebut.

\section{DAFTAR PUSTAKA}

1. Cleland J, et al. Associations between Medical School and Career Preferences in Year 1 Medical Students in Scotland. Blackwell Publishing. 2012; 46: 473484.

2. Bhat, Smitha, Landric D'souza dan Jeffrey Fernandez. Factors Influencing the Career Choices of Medical Graduates. 2012; 49: 482-489

3. Yamazaki Y, Takanori U. Japanese Medical Students' Interest in Basic Science : A Questionnaire Survey of a Medical School in Japan. 2013; 229:129-136

4. Patel MS, Katz JT, Volpp KG. Match Rates into Higher Income, Controllable Lifestyle Specialities for Students from Highly Ranked, Research-Based Medical Schools Compared with Other Applicants. J.Grad.Med.Educ. 2010; 2: 360-365.

5. Soethout MBM, Heymans MW. Career Preference and Medical Students' Biographical Characteristics and Academic Achievement. Med Teach. 2008; 30: $15-30$.

6. Dorsey ER, Jarjouram D, Rutecki GW. The Influence of Controllable Lifestyle and Sex on the Specialty Choices of Graduating US Medical Students, 19962003. Acad Med. 2005;80:791-6.

7. Lambert EM, Holmboe ES. The Relationship between Specialty Choice and Gender of US Medical Students,1990-2003. Acad Med. 2005;80:797-802.

8. National Records of Scotland. Statistics on Population and Demographics in Scotland: Assessment Report 13. Edinburgh: NRS; 2011.

9. Richards P, Stockill S. Career Opportunities. Dalam: Learning Medicine: An Informal Guide to Career in Medicine. Edisi 16. London. BMJ Books; 2003: 11832.

10. Fork H. Career Options. Doctors Crossing; 2010. (http://doctorscrossing.com/career-options/diakses 16 November 2013).

11. Santiago A. Non-Clinical Medical Jobs for Physicians. Health Careers; 2013.

12. Newton DA, Grayson MS, Thompson LF. The Variable Influence of Lifestyle and Income on Medical Students' Career Specialty Choices: Data from Two U.S. Medical Schools, 1998-2004. Acad Med. 2005 Sep;80(9):809-14. 
13. Morra DJ, Regeher G, Ginsburg S. Medical Students, Money, and Career Selection: Students' Perception of Financial Factors and Remuneration in Family Medicine. Fam Med. 2009;41(2):105-10.

14. Kuikka L, Nevalainen MK, Sjoberg L, Salokekkilä P, Karppinen H, Torppa M, Liira H, Eriksson J, Pitkälä $\mathrm{KH}$. The perceptions of a GP' s work among fifthyear medical studentsin Helsinki, Finland. Scand J Prim Health Care. 2012; 30: 121-126

15. Riska E. Gender and Medical Careers. Maturitas. 2011, 68:264-7.

16. Gill H, McLeod S, Duerksen K, Szafran O. Factors Influencing Medical Students' Choice of Family Medicine. Can Fam Physician. 2012;58:e649-57

17. Irfan A. Dhalla, Jeff C. Kwong, David L. Streiner, et al. Characteristics of First-Year Students in Canadian Medical Schools. CMAJ. 2002;166(8):1029-35 1819
18. Kementerian Kesehatan Republik Indonesia. Jumlah dan Rasio Tenaga Kesehatan: Profil Kesehatan Indonesia. 2012. Jakarta: Kemenkes RI; 2013.

19. Al-Fouzan R, Al-Ajlan S, Marwan Y, Al-Saleh M. Factors affecting future specialty choice among medical students in Kuwait. Med Educ Online. 2012;17:1-7.

20. Kaufman SB. The Complexity of Greatness: Beyond Talent Or Practice. Oxford University Press; 2013. $464 \mathrm{p}$.

21. Patton W, McMahon M. Career Development and Systems Theory: Connecting Theory and Practice. Sense Publishers; 2006. 409 p.

22. Diderichsen S, Johansson EE, Verdonk P, LagroJanssen T, Hamberg K. Few gender differences in specialty preferences and motivational factors: a crosssectional Swedish study on last-year medical students. BMC Med Educ. 2013;13:39. 